\title{
Filippo Tommaso Marinetti, Valentine de Saint-Point oder die Anfänge der historischen Avantgarde
}

Kommen wir nun zur ersten großen Figur der historischen Avantgarden und damit zu jenem Mann, ohne den keine Geschichte der historischen Avantgarden auskommen kann: dem Italiener Marinetti, dem legendären Begründer des italienischen und bald auch über Italien hinausreichenden Futurismus!

Der 1876 in Alexandria (Ägypten) geborene Marinetti wurde französisch erzogen, flog wegen religionskritischer Machenschaften von der lokalen Jesuitenschule, holte sein Abitur in Paris nach und studierte als Sohn eines wohlhabenden Rechtsanwalts in Pavia Rechtswissenschaften, bevor er sich der Literatur zuwandte und in Paris sein Domizil aufschlug. Er arbeitete als freier Mitarbeiter bei verschiedenen Zeitungen in der französischen Hauptstadt: für Le Figaro, La Plume sowie La Vogue. Marinetti unternahm auch Rezitationsreisen durch Frankreich, auf denen er neben eigenen Gedichten Werke von Mallarmé, Baudelaire, Rimbaud, Verlaine und Gustave Kahn vortrug.

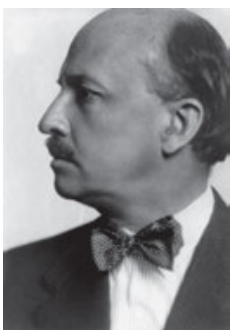

Abb. 17: Filippo Tommaso Marinetti (Alexandria, Ägypten, 1876 Bellagio, 1944).

Zur Durchsetzung der Symbolisten und des französischen „vers libre“ in Italien gründete der zeitweise nach Mailand übergesiedelte Marinetti zusammen mit dem Schriftsteller Gian Pietro Lucini die Literaturzeitschrift Poesia, deren erste Ausgabe auch Werke von Gabriele d'Annunzio enthielt. Die Zeitschrift plädierte für einen radikalen literarischen Neuanfang. Seine ersten schriftstellerischen Werke siedeln sich im großbürgerlichen Milieu des Fin de siècle an und sind von einem starken Kulturpessimismus geprägt. Der junge Marinetti war fasziniert von den damaligen Gewalttaten der Anarchisten, mit denen er sympathisierte, erblickte er doch in den anarchistischen Attentaten den Versuch, alle normierten Lebensverhältnisse aufzusprengen. Ein Manifest von Georges Sorel, einem Theoretiker der Anarchie, aus dem Jahr 1907 prägte den noch jungen Italiener stark. 


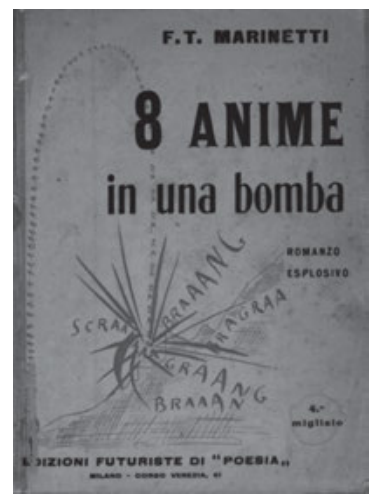

Abb. 18: Filippo Tommaso Marinetti (Hg.): 8 anime in una bomba. Romanzo esplosivo. Mailand: Edizioni futuriste di „Poesia“ 1919.

Am 20. Februar 1909 begründete Marinetti den Futurismus mit dem in Le Figaro auf der Titelseite selbstverständlich in französischer Sprache erschienenen Manifest des Futurismus, mit dem wir uns gleich beschäftigen werden. Kurze Zeit später veröffentlichte er seinen ersten futuristischen Roman, Mafarka le futuriste, der ihm eine Anklage wegen Verstoßes gegen die Sittlichkeit einbrachte. Das war durchaus intendiert: Der aus großbürgerlichem Hause stammende Marinetti war auf Revolte gebürstet und stand - wie auch später in seinem Leben - ebenso faschistischen wie sozialistischen und anarchistischen Ideen offen gegenüber.

1912 ging Marinetti als Kriegsberichterstatter nach Libyen. Um den Futurismus zu propagieren, reiste er von Italien aus nach Paris, London, Berlin, Amsterdam, Moskau und St. Petersburg. Das väterliche Erbe half, die vielfältigen Aktivitäten von Marinetti und seiner futuristischen Künstlergruppe, deren Schwerpunkte in den Bereichen Literatur und Malerei lagen, aber auch die anderen Künste nicht vernachlässigten, zu unterstützen. Seit Marinetti 1910 unter italienischen Künstlern Mitstreiter für seine Bewegung gefunden hatte, lebte er hauptsächlich in Mailand und agitierte entschlossen für den Krieg. So trommelten die Futuristen für den Großen Krieg, in dem viele ihr Leben ließen. Marinetti selbst wurde zu einem glühenden nationalistischen Verfechter des Interventionismus. 1916 meldete er sich zum Radfahrerbataillon und nahm am Ersten Weltkrieg teil.

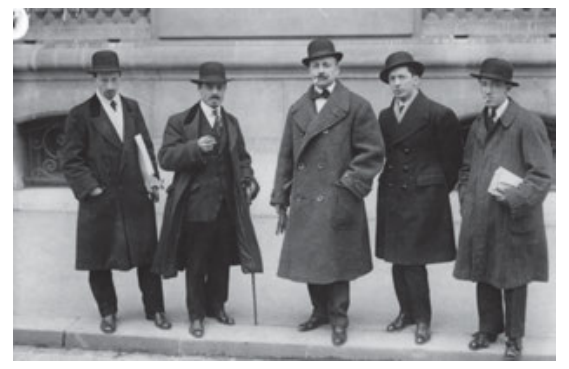

Abb. 19: Die futuristische Künstlergruppe um Tommaso Marinetti, vor dem Gebäude der Zeitschrift Le Figaro im Februar 1912. 
1918 verfasste er das Manifest der futuristischen Partei und verlagerte seine Aktivitäten stärker in den Bereich der Politik. 1919 trat Marinetti den Faschistenbünden Mussolinis bei und reihte sich in der gewaltbereiten Rechten ein. Seine Futuristische Partei ging bald schon in der Bewegung Mussolinis auf, der vieles von den Futuristen übernahm. Marinetti selbst aber zog sich immer mehr vom italienischen Faschistenführer zurück und widmete sich allen Bereichen der futuristischen Künste, vor allem dem Theater.

Entwickelte sich Marinetti auch zeitweise hin zum Anarchismus, so näherte er sich doch ab 1924 wieder den Faschisten Mussolinis an, die seit 1922 in Italien an der Macht waren. 1929 wurde er zum Mitglied der Accademia d'Italia berufen, die er lange Zeit geschmäht hatte: Er war nun definitiv ein arrivierter Künstler. Marinetti und der Futurismus avancierten zu den künstlerischen Ikonen und Vorbildern des europäischen Faschismus und wurden auch ab 1933 von den deutschen Nationalsozialisten begrüßt. Der Begründer des Futurismus wandte sich zwar gegen alle Rassegesetze und gegen die Verstoßung sogenannter ,entarteter Kunst, feierte aber bis zu seinem Tod die Schönheit des Krieges in kühnen Bildern. 1944 starb er in Bellagio (Como).

Nun aber zum ersten Manifest des Futurismus! Wir kommen später auf die Bedeutung jener Gattung zu sprechen, die wie keine andere die der historischen Avantgarde ist: das Manifest. Ich möchte Ihnen gerne das Gründungsmanifest des Futurismus in deutscher Übersetzung sowie im Anhang in Marinettis eigener italienischer Übersetzung präsentieren, die überaus erfolgreich und verbreitet war. Unterzeichnet wurde es von Marinetti allein, und doch ist der kollektive Charakter vom ersten Augenblick an spürbar - ganz im Sinne des Begründers, der seine Bewegung damals erst noch schaffen musste. Es setzt mit seinen beiden ersten Abschnitten wie folgt ein:

Wir haben die ganze Nacht gewacht - meine Freunde und ich - unter den Moscheeampeln mit ihren durchbrochenen Kupferschalen, sternenübersät wie unsere Seelen und wie diese bestrahlt vom eingefangenen Glanz eines elektrischen Herzens. Lang haben wir auf weichen Orientteppichen unsere atavistische Trägheit hin und her getragen, bis zu den äußersten Grenzen der Logik diskutiert und viel Papier mit irren Schreibereien geschwärzt.

Ein ungeheurer Stolz schwellte unsere Brust, denn wir fühlten, in dieser Stunde die einzigen Wachen und Aufrechten zu sein, wie stolze Leuchttürme oder vorgeschobene Wachposten vor dem Heer der feindlichen Sterne, die aus ihren himmlischen Feldlagern herunterblicken. Allein mit den Heizern, die vor den höllischen Kesseln der großen Schiffe arbeiten, allein mit den schwarzen Gespenstern, die in den Bäuchen der der wie wild dahinrasenden Lokomotiven wühlen, allein mit den Betrunkenen, die mit unsicherem Flügelschlag an den Stadtmauern entlang torkeln. ${ }^{1}$

1 Marinetti, Filippo Tommaso: Gründung und Manifest des Futurismus. In: Asholt, Wolfgang / 
Von Beginn an haben wir es mit einer Gruppe zu tun, die sich in diesen Passagen selbst in Szene setzt. Der kollektive Charakter wird - trotz der singulären, individuellen Unterzeichnung, die in der Folge eher zur Ausnahme werden sollte, durch den von Beginn an eingefügten Hinweis auf die Mitstreiter, die Freunde, erzeugt. Dies ist übrigens ein literarisches Verfahren, das Sie in vielen Texten aus der Feder Friedrich Nietzsches finden können, wo sich der Philosoph stets aus der Position des Lehrmeisters und Vordenkers anspornend und auffordernd an seine Brüder im Geiste richtet und damit eine Gemeinsamkeit im Kampf beschwört, die sich oft genug gegen die Herden-Menschen und den Herden-Instinkt wendete. Ein nietzscheanischer Ton ist im Gründungsmanifest des Futurismus nicht zu überhören, das nietzscheanische Erbe allgegenwärtig!

Das zweite Element, das in diesem Gründungsmanifest ins Auge springt, ist die Tatsache, dass die vorwiegend diskursive Textsorte des Manifests hier von Beginn an mit dominant narrativen Zügen ausgestattet wird, was natürlich nicht heißt, dass das diskursive Element etwa verschwände. Es kommt vielmehr im zweiten Teil des Manifests, mit dem wir uns gleich beschäftigen werden, in umso konzentrierterer Form zum Tragen: als Programm. Zunächst aber wird eine Geschichte erzählt, eine Geschichte übrigens, die im Zeichen von Geschwindigkeit, Gefahr, Gewalt und Unfall, aber auch Überleben und einem gestärkt aus der Prüfung Hervorgehen besteht. Denn der Ich-Erzähler fährt in diesem ersten Teil des Manifests Auto, und zwar sehr schnell, so dass er letztlich mit seinem geliebten „Haifisch“ im Straßengraben landet, woraus man ihn und sein Gefährt wieder ziehen muss. Zuvor freilich trinkt er noch den Industrieschlamm des Straßengrabens, saugt ihn gierig in sich auf wie einst die Milch einer schwarzen Amme, und kann sich solchermaßen industriell gestärkt an die Abfassung des programmatischen Teils seines Manifests machen.

Bevor wir zu diesem Teil kommen, seien aber noch einige kurze Bemerkungen erlaubt: Die Eingangsszene einer durchwachten Nacht, die in ein gewisses religiöses Licht getaucht ist, wird vom elektrischen Licht und der Metapher des Elektrischen überhaupt erhellt. Es ist zunächst der Blick zurück auf die Orientteppiche des Fin de siècle und den Atavismus, auf Trägheit und Bewegungslosigkeit, die hier ganz offensichtlich mit dem Orientalismus des Jahrhundertendes und der Dekadenz in Verbindung gebracht und zugleich überwunden werden sollen. Die erste Szenerie vermittelt damit den Augenblick von Stillstand und vor allem Aufbruch, den Marinetti, der als Direktor der Zeitschrift Poesia firmiert, in der auch noch Gedichte des späteren Rivalen Gabriele d'Annunzio veröffentlicht wurden,

Fähnders, Walter (Hg.): Manifeste und Proklamationen der europäischen Avantgarde (1909-1938). Stuttgart - Weimar: Verlag J.B. Metzler 1995, S. 3. 
ganz bewusst akzentuiert. Das Gründungsmanifest des Futurismus eröffnet seine Zukunftsvision folglich nicht aus dem Nichts, sondern konturiert einen soziokulturellen Kontext, der radikal verlassen wird.

Von Beginn an sind die Vertreter des Ich - das kollektive Wir - die einzig Wachen in einer verschlafenen Zeit, die Leuchttürme und Wachposten, womit zwei metaphorische Ebenen eingeblendet werden, die für den gesamten Text von Bedeutung sind. Zum einen wird damit die Welt der technischen Artefakte aufgerufen und - damit verbunden - andererseits die bereits erwähnte Metaphorik von Krieg und Vorhut. Als Wachposten vor dem Heer der feindlichen Sterne wird diese kriegerische Dimension sozusagen intergalaktisch ausgedehnt. In der Tat gibt es eine Vielzahl von Bezügen futuristischer Texte zu Science-Fictionartigen Elementen, zur Eroberung intergalaktischer Räume und zur Ausweitung des Krieges nicht nur in den Bereich der Luft - die Bezeichnung Luftkrieg wird unwesentlich später geprägt werden -, sondern auch in den Bereich der aktuellen Star Wars hinein. Längst haben die Futuristen die Luft und den Weltraum für sich erobert: Der Luftkrieg sollte eine ,Errungenschaft‘ des Ersten Weltkrieges werden ${ }^{2}$ und die Eroberung des Weltraums unmittelbar an das Ende des Zweiten Weltkriegs anschließen! Man kann den Futuristen einen gewissen Realitätsbezug nicht absprechen.

Futuristisch ist auch die Dimension von Moderne, Mensch und Maschine eingefärbt. Der Dimension des Maschinenhaften kommt dann eine große Bedeutung zu, wenn sie zugleich mit äußerster Anspannung und mehr noch mit wilder Bewegung gekoppelt ist. Es ist diese Bewegung, die das Ich des Textes - aber natürlich auch Marinetti selbst - aufs Äußerste anzieht und ästhetisch verführerisch wirkt. Die Lokomotive wird hier zu einem Emblem der Motion, wenn sie auch längst zum Emblem der Moderne und Modernisierung im 19. Jahrhundert geworden war. An dieser Stelle freilich interessiert sie auch als Verkörperung einer nicht mehr nur kontrollierten Bewegung, sondern auch eines wilden Dahinrasens, eines Aspekts, der auch schon in Emile Zolas La bête humaine sehr plastisch in der Unkontrollierbarkeit von Technik hervorgetreten war. Wir sollten diesen Aspekt nicht vergessen: Es ist keineswegs, wie oft behauptet wird, allein die Verfügbarmachung von Natur und die Lobpreisung der Maschine, sondern gerade auch das AußerKontrolle-Geraten, das die Futuristen und allen voran Filippo Tommaso Marinetti interessiert und fasziniert.

2 Vgl. Ingold, Felix Philipp: Literatur und Aviatik. Europäische Flugdichtung 1909-1927. Mit einem Exkurs über die Flugidee in der modernen Malerei und Architektur. Frankfurt am Main: Suhrkamp 1978. 
Bleiben wir noch einen Augenblick bei der Frage der Narrativität dieses ersten Teils des Gründungsmanifests des italienischen Futurismus! Denn hier zeigt sich, dass der Einbau der Erzählung und des erzählerischen Elements das Manifest nicht nur als metaliterarischen und metakünstlerischen Text erscheinen lässt, wie dies im Allgemeinen zuvor der Fall gewesen war (und wie es der zweite Teil des Manifests auch praktizieren sollte). Vielmehr stellt dieser Teil einen im engeren Sinne literarischen Text dar, der seinen eigenen Artefakt-Charakter auch zu inszenieren und herauszustreichen versteht. Das Gründungsmanifest des Futurismus ist daher nicht nur als ein theoretischer, diskursiver, selbstreflexiver und metasprachlicher Text zu verstehen, sondern selbst wiederum als Ausübung einer künstlerischen Praxis zu begreifen, welche auch das Manifest selbst umfasst. Ich werde auf diese Fragestellung nochmals zurückkommen, doch sei schon jetzt gesagt, dass diese narrative und zugleich polyseme Dimension viel zum internationalen Erfolg des Manifests beitrug.

Der abrupte Übergang dieses narrativen Texts zum diskursiven, programmatischen Teil wird zugleich betont und in seiner Verschiedenartigkeit herausgestrichen. Dies ist nicht zuletzt durch die Beendigung des Narrativen signalisiert, die als eine Art ,Geburtsvorgang‘ bezeichnet wird, indem nämlich kollektiv ein erster Wille diktiert wird, welcher sich direkt an alle lebendigen Menschen richtet. Schauen wir uns diesen ersten Willen, das Gegenteil eines Testaments oder letzten Willens also, einmal näher an! Denn es handelt sich dabei um den Ausdruck eben eines Willens, eines Kunstwollens und Gestalten-Wollens, und mehr noch: um ein ästhetisches Wollen, das sich an die Stelle anderer Ästhetiken setzt. Dies beinhaltet auch einen gewissen diktatorischen Zug, der zugleich ein Licht auf die weitere Entwicklung des italienischen Futurismus wirft. Wir erinnern uns, der kühne Automobilist ist gerade seinem „Haifisch“ im Straßengraben entstiegen:

Da, das Antlitz vom guten Fabrikschlamm bedeckt - diesem Gemisch aus Metallschlacke, nutzlosem Schweiß und himmlischem Ruß - zerbeult und mit verbundenen Armen, aber unerschrocken, diktieren wir unseren ersten Willen allen lebendigen Menschen dieser Erde:

\section{Manifest des Futurismus}

1. Wir wollen die Liebe zur Gefahr besingen, die Vertrautheit mit Energie und Verwegenheit.

2. Mut, Kühnheit und Auflehnung werden die Wesenselemente unserer Dichtung sein.

3. Bis heute hat die Literatur die gedankenschwere Unbeweglichkeit, die Ekstase und den Schlaf gepriesen. Wir wollen preisen die angriffslustige Bewegung, die fiebrige Schlaflosigkeit, den Laufschritt, den Salto mortale, die Ohrfeige und den Faustschlag.

4. Wir erklären, dass sich die Herrlichkeit der Welt um eine neue Schönheit bereichert hat: die Schönheit der Geschwindigkeit. Ein Rennwagen, dessen Karosserie große Rohre schmücken, die Schlangen mit explosivem Atem gleichen ..., ein auf- 
heulendes Auto, das auf Kartätschen zu laufen scheint, ist schöner als die Nike von Samothrake.

5. Wir wollen den Mann besingen, der das Steuer hält, dessen Idealachse die Erde durchquert, die selbst auf ihrer Bahn dahinjagt. [...]

9. Wir wollen den Krieg verherrlichen - diese einzige Hygiene der Welt - den Militarismus, den Patriotismus, die Vernichtungstat der Anarchisten, die schönen Ideen, für die man stirbt, und die Verachtung des Weibes.

10. Wir wollen die Museen, die Bibliotheken und die Akademien jeder Art zerstören und gegen den Moralismus, den Feminismus und gegen jede Feigheit kämpfen, die auf Zweckmäßigkeit und Eigennutz beruht.

11. Wir werden die großen Menschenmengen besingen, die die Arbeit, das Vergnügen oder der Aufruhr erregt; besingen werden wir die vielfarbige vielstimmige Flut der Revolutionen in den modernen Hauptstädten [...]. ${ }^{3}$

Es ist an dieser Stelle der Vorlesung leider nicht möglich, alle Dimensionen (und Thesen) des hier nur ausschnitthaft zitierten zweiten Teiles des Manifests zu erfassen, müssten wir im Grunde doch mehr als eine ganze Sitzung auf diese Problematik verwenden, wollten wir den einzelnen Punkten und ihrer späteren Entwicklung wirklich gerecht werden. Doch sei an dieser Stelle zunächst einmal darauf verwiesen, dass das Besingen der Liebe zur Gefahr, wie es im ersten Punkt des Manifests betont wird, deutlich eine Anleihe an Friedrich Nietzsche darstellt, eine Anleihe an den nicht genannten Vorläufer, dessen Denk- und Schreibstil aber zweifellos überall präsent ist. Denn Nietzsche besingt gerade diese Liebe zur Gefahr, die sich nicht zuletzt auch im Wagemut der Philosophie und sicherlich nicht weniger im Wegwerfen des eigenen Lebens im Krieg - im Zeichen des Heroismus - sonnt. Auch die entschlossene Misogynie, auf die wir noch zu sprechen kommen werden und die auch in den europäischen Faschismus einging, ist ein Erbe von Nietzsche, selbst wenn der deutsche Philosoph sicherlich nicht der einzige Frauenfeind in der europäischen Kulturgeschichte war.

Es überrascht nicht, dass die charakteristischen Gesten, die in diesem Manifest genannt werden, im Grunde Gesten der Aggressivität und Verachtung sind, einer oftmals körperlichen Aggressivität, die von den Avantgardisten auch in den folgenden Jahren in der Tat mehrfach, ja vielfach, im öffentlichen Raum benutzt wurden. Sind wir heute, was diese Dimension alltäglicher Gewalt und das Aufkommen nationaler Faschismen nach dem Ende unserer vierten Phase beschleunigter Globalisierung angeht, wirklich so weit von den Ausdrucksformen dieser Zeit entfernt? Ist etwa die Lobpreisung der Gewalt in einer Zeit nicht angesagt,

3 Marinetti, Filippo Tommaso: Gründung und Manifest des Futurismus. In: Asholt, Wolfgang / Fähnders, Walter (Hg.): Manifeste und Proklamationen der europäischen Avantgarde (1909-1938), S. $4 \mathrm{f}$. 
in welcher der Präsident des wichtigsten Landes der sogenannten westlichen Wertegemeinschaft mit seiner Frauenfeindlichkeit prahlt und er für seine misogynen Bemerkungen (unter anderem auch von Frauen) gewählt wird? Damit will ich freilich nicht sagen, dass dieser Präsident ein Avantgardist wäre! Es geht mir aber sehr wohl um ein allgemeines gesellschaftliches Klima, in welchem Gewalt und faschistoides Verhalten Konjunktur haben. Doch verzeihen Sie bitte diesen kurzen Seitenblick!

Die Geste der Ohrfeige findet sich in vielen futuristischen Happenings, nicht zuletzt auch in Russland, wo der Futurismus eine eigene Entwicklung nahm und dabei auch gegenüber dem italienischen Futurismus - wohl aufgrund von Fälschungen - eine Vorreiterschaft, ja eine auch zeitliche Priorität für sich reklamieren konnte. In vielen Ländern ist die Ohrfeige das spektakuläre Mittel, um mit dem Traditionellen, dem Bewährten, dem Selbstverständlichen und dem Konventionell-Selbstzufriedenen Schluss zu machen und einen Bruch anzudeuten. Denken Sie etwa an die Wirkung der berühmten Ohrfeige von Beate Klarsfeld für den Ministerpräsidenten Filbinger, der sich über seine Nazi-Vergangenheit ausschwieg. Es sind Gesten der Polemik, des Kampfes, des Sich-an-die-Stelle-des-Bisherigen-setzen-Wollens, einer totalen Abrechnung mit der Vergangenheit, die hier von entscheidender Bedeutung sind. Umgesetzt in den Bereich des Ästhetischen und der Kunst werden diese Elemente als Kühnheit und Auflehnung erscheinen: auch hier als Geste des Bruches, eines bewussten Ausbrechens aus der bisherigen Tradition und Geschichte.

Bleiben wir im Bereich des Ästhetischen! Denn, so Marinetti in seiner recht charakteristischen Großspurigkeit, die Welt habe sich durch eine neue Schönheit bereichert, eine Schönheit, die er von nun an zu preisen nicht mehr aufhören konnte und die in der Tat die weitere Entwicklung aus vielfältiger Perspektive verändern sollte. Diese neue Schönheit ist die der Geschwindigkeit, ja des Rausches der Geschwindigkeit. Geschwindigkeit ist dabei sowohl ein Wahrnehmungsphänomen, insoweit nun alle Objekte aus der Perspektive des Fahrens, Fliegens oder des Sich-wie-auch-immer-Bewegens wahrgenommen werden, also eine grundlegende Wahrnehmungsveränderung mit sich bringen.

Ein gutes Beispiel für diese Wahrnehmungsveränderungen sind die photographischen Aufnahmen von sich rasch bewegenden Objekten im medialen Bereich wie auch etwa - auf dem Gebiet der Dichtkunst - Oliverio Girondos Veinte poemas para ser leídos en el tranvía, wobei sich bei diesen kurzen Gedichten die Wahrnehmung der Geschwindigkeit und Bewegung mit jener der Dichtkunst koppelt. Darüber hinaus ist es aber auch die Ikone der Geschwindigkeit, also der Rennwagen, der hier mit all seinen Farben und Formen vorgestellt wird als Verkörperung dieses neuen Gefühls für die hohe Geschwindigkeit. Denken Sie hier in Berlin etwa an die nur wenige Jahre nach unserem Manifest beginnende 
Konstruktion der AVUS, der Automobil-Verkehrs- und Übungsstraße, und an die Hochgeschwindigkeitsrekorde, die bald politisch vereinnahmt wurden! An spektakulären Unfällen, die im Straßengraben endeten, sollte es nicht mangeln ...

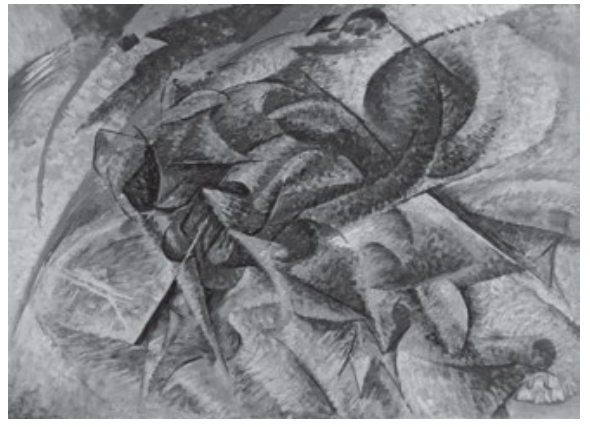

Abb. 20: Umberto Boccioni: Dynamik eines Radfahrers, Öl auf Leinwand, 1913.

Wir hatten gesehen, dass diese Geschwindigkeit sich bereits im narrativen Teil in einer rasenden, stets kippenden Wahrnehmung gezeigt hatte, die den Protagonisten mitsamt seinem Automobil schließlich in die Tiefe eines Schlammgrabens am Rande der Straße schleudern sollte. Diese Gefährlichkeit ist aber gerade das positive Element, gleichsam der „Thrill“ der Avantgardisten. Des Weiteren zeigt sich hierin auch eine Ästhetisierung und Verherrlichung der Maschine, die gleichsam zur Prothese des Männlichen wird. Dabei ist freilich das Weibliche - entgegen der Werbung, die heute mit schnellen Automobilen und Frauen betrieben wird - keineswegs angelockt und fasziniert von der Männlichkeit der Maschine, wird diese auch mit all ihren Rohren zur Schau gestellt. Die Frau wird bei den Futuristen folglich nicht zum verführten Objekt und umgekehrt zum Subjekt erotischer Verführung, sondern aus dem Bereich nicht nur der Verführung, sondern der Ästhetik überhaupt ausgeschlossen. Im Gründungsmanifest der Futuristen hat sich die Männlichkeit der blitzenden Rohre, die Schlangen gleichen und leicht explodieren, an die Stelle des Weiblichen gesetzt, Kraft und Härte an die Stelle des Flexiblen und Runden.

Selbst der Schrei wird der Schönen aus dem Mund genommen; denn an seine Stelle tritt das Aufheulen des Autos, der Maschine - wie das Auto ja auch im Italienischen heißt -, die gleichsam auch den erotischen, den sexuell-körperlichen Bereich der Männlichkeit befriedigt. Wir werden auf diese Dimension im weiteren Verlauf der Avantgarde noch mehrfach zurückkommen. Und doch scheint es mir an dieser Stelle notwendig, einen kleinen Verweis einzubauen, war diese Problematik doch schon einer frühen Avantgardistin sehr gegenwärtig und bewusst. Sie setzte sich in der Folge dann auch tatsächlich in eigenen Manifesten unter anderem auch mit dieser Fragestellung auseinander. Ihre künstlerische Arbeit 
bildet gleichsam das geschlechterspezifische Gegengewicht zum unbestrittenen Männlichkeitskult der italienischen und europäischen Futuristen.

Noch vor wenigen Jahren ergab ein kurzer Test, dass die französische Futuristin, von der ich spreche, nämlich Valentine de Saint-Point, in den mir zur Verfügung stehenden einschlägigen Nachschlagewerken und Literaturgeschichten ganz und gar nicht verzeichnet war. Sie findet sich weder in der neuen französischen Literaturgeschichte bei Metzler noch im neuen Kindler, weder in Harenbergs Lexikon noch in Englers Nachschlagewerk, weder in der Sozialgeschichte der französischen Literatur des 20. Jahrhunderts noch in anderen Nachschlagewerken, um nur einige Beispiele herauszugreifen. Es hat sich freilich in jüngster Zeit etwas geändert, denn immerhin wird sie auf weniger als zehn Zeilen in Wikipedia erwähnt und kurz konturiert.

Was ich Ihnen gemäß meiner eher dürftigen Informationslage von Valentine de Saint-Point sagen kann ist, dass sie als Anne Jeanne Valentine Marianne Desglans de Cessiat-Vercell 1875 in Lyon geboren wurde und 1953 in Kairo verstarb genauere Daten habe ich nicht. Sie trat aus futuristischer Sicht vehement für ein neues Frauenbild ein, verwahrte sich aber gegenüber feministischen Positionen. Aufschlussreich ist, dass sie laut Wikipedia 1924 nach Ägypten zog, den Namen Rawhiya Nour-ed-Dine (gleich „Fanatikerin des Lichts des Glaubens“) annahm und den muslimischen Kampf gegen den europäischen Imperialismus unterstützte. Sie stand damit auch politisch wie militärisch auf der ,anderen Seite‘, agierten die meisten männlichen Futuristen doch im Sinne eben dieser imperialistischen Mächte und verteidigten etwa das imperiale Vordringen Italiens auf dem afrikanischen Kontinent. Sie war als Dichterin wie auch als futuristische Agitatorin zweifellos eine Außenseiterin, doch eben dies macht sie so interessant.

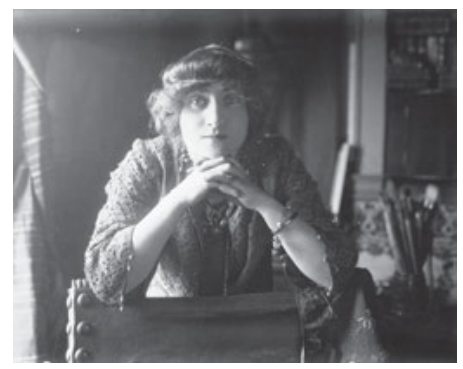

Abb. 21: Valentine de Saint-Point (Lyon, 1875 Kairo, 1953)

Wichtig für unsere Vorlesung ist, dass sie am 25. März 1912 von Paris aus ein kämpferisches Manifest aus futuristischer Perspektive gegen Marinettis Geschlechtersicht veröffentlichte, aus dem ich Ihnen in der Folge zwei Passagen gerne vorstellen möchte. Es hatte bei weitem nicht die breite internationale Wirkung, wie 
sie die Manifeste Marinettis besaßen; doch gibt es etwas von jenem Kampf wieder, der nicht zuletzt auch gegen den faschistoiden Männlichkeitswahn von Frauen geführt wurde, die aus der Literaturgeschichte rasch wieder verdrängt und getilgt wurden. Eine wirkliche Geschichte der Frauen in den Anfängen der historischen Avantgarden und speziell des Futurismus wird erst noch zu schreiben sein. Mir scheint in jedem Falle, dass die Positionen von Valentine de Saint-Point sehr präzise die patriarchalischen Positionen des Futurismus beleuchten:

ES IST ABSURD, DIE MENSCHHEIT IN FRAUEN UND MÄNNER EINZUTEILEN. Sie besteht nur aus WEIBHEIT und MANNHEIT. Jeder Übermensch, jeder Held, sei er noch so episch, jedes Genie, sei es noch so mächtig, ist nur der verschwenderische Ausdruck einer Rasse und einer Epoche, weil es eben aus weiblichen und männlichen Elementen besteht, aus Weibheit und Mannheit: weil es ein vollkommenes Wesen ist.

Ein nur-männliches Individuum ist ein Vieh, ein nur-weibliches Individuum ein Weibchen. [...]

Die Zeiten, die nur heldenlose Kriege hatten, weil der epische Hauch alle gleichmachte, waren ausschließlich Epochen der Männer; die Zeiten, die den heroischen Instinkt verleugneten und die, der Vergangenheit zugewandt, sich in Friedensträumen verzehrten, waren Epochen der Frauen.

Wir leben am Ende einer dieser Zeitläufte. WAS DEN FRAUEN EBENSO WIE DEN MÄNNERN AM MEISTEN FEHLT, IST MANNHEIT. ${ }^{4}$

In dieser ersten hier angeführten Passage wendet sich Valentine de Saint-Point, die zuvor eine Passage aus Marinettis Manifest zitiert hatte, in dem die Frauenfeindlichkeit des Manifests deutlich hervorgetreten war, der Problematik der Geschlechterdifferenz zu, wobei sie zunächst eine Aufteilung der Menschheit in Männer und Frauen kategorisch ablehnt. Was sie in einem zweiten Schritt freilich akzeptiert, ist eine Unterscheidung zwischen „Mannheit“ und „Weibheit“, also sozusagen ontologischen und essentiellen, im Sein des Menschen selbst verankerten Wesenheiten, die aber sowohl auf die Männer als auch auf die Frauen verteilt sind. Jeder Frau kommen damit auch männliche, jedem Mann auch weibliche Elemente zu. So weit, so gut!

An diesem Punkt aber reklamiert Valentine de Saint-Point für die Frauen Anteil an der Mannheit, wobei sie gerade auch sie in Bezug zum Krieg setzt, der 1912 noch ganz in der Ferne eines solchen argumentierend - als eine Art futuristisches Spektakel in ihrem Manifest erscheint. Der Krieg ist also keineswegs allein Sache der Männer! Er erscheint vielmehr als eine Art Durchgang zu einer besseren Zeit, in der sich die Zukunftsträume der Menschheit erfüllen werden. Diese Zukunfts-

4 Saint-Point, Valentine de: Manifest der futuristischen Frau. In: Asholt, Wolfgang / Fähnders, Walter (Hg.): Manifeste und Proklamationen der europäischen Avantgarde (1909-1938), S. 22. 
träume sind, wie wir unschwer erkennen, keineswegs mit den Friedensträumen der Frauen identisch, sondern auf Konflikt, Auseinandersetzung und mehr noch gewalttätige Durchsetzung hin angelegt. Die Frauen wollen dabei nicht länger ihrer althergebrachten Geschlechterrolle entsprechen, sie wollen mehr Mannheit in sich aufnehmen und ihre Lage verändern. Damit aber greift Valentine de SaintPoint auf einer anderen Ebene auf die althergebrachten Geschlechterstereotype zurück, die sie in ihrem Manifest keineswegs in Frage stellt. Es geht ihr dennoch im Wesentlichen darum, die Frau nicht nur als Frau und den Mann nicht nur als Mann zu verstehen, sondern sie in dynamische Austauschbeziehungen zu versetzen. Das ist eine klare Abkehr von Marinettis misogynem Männlichkeitswahn, dem wir durchaus faschistoide Züge bescheinigen dürfen.

Wie aber steht es jenseits von Mannheit und Weibheit mit den Frauen selbst? Welche Rolle kommt ihnen in der künftigen Gesellschaft zu? Wir finden in diesem Manifest der futuristischen Frau von 1912 hierauf erste Antworten:

Die Wollust ist eine Kraft, weil sie die Schwachen zermalmt, die Starken zur Hingabe von Kräften, also zu ihrer Erneuerung erregt. Jedes heroische Volk ist sinnlich. Die Frau ist der verlockendste Preis.

Die Frau muß Mutter oder Geliebte sein. Wahre Mütter sind immer mäßige Geliebte, und Geliebte mäßige Mütter. Im Leben ergänzen sich beide. Die gebärende Mutter bringt mit der Vergangenheit die Zukunft, die Geliebte verkündet die Sehnsucht nach der Zukunft.

Schluß: die Frau, die durch ihre Tränen und durch ihre Sentimentalität den Mann zu ihren Füßen zurückhält, ist verächtlicher als das Mädchen, das aus Prahlerei ihren Liebhaber dazu treibt, mit dem Revolver in der Hand seine prahlerische Herrschaft über die Niederungen der Stadt zu behaupten; es zeigt wenigstens eine einer besseren Sache würdige Energie. Frauen, ihr wart zu lange in Moral und Vorurteilen irrgläubig; kehrt zu eurem erhabenen Instinkt zurück, zur Wildheit, zur Grausamkeit.

Während die Männer sich bekriegen und kämpfen, schafft ihr Kinder als blutigen Tribut für den Krieg und den Heroismus, denkt an die Forderung des Schicksals. Laßt sie wachsen, nicht für euch, für eure Vergnügen, sondern in schrankenloser Freiheit zur Blüte.

Statt die Männer unter das Joch der erbärmlichen sentimentalen Bedürfnisse zu bringen, treibt eure Söhne, eure Männer, sich selbst zu übertreffen.

Ihr schafft sie. Ihr könnt alles über sie. Ihr schuldet der Menschheit Helden. Gebt sie ihr! ${ }^{5}$

Es sind erstaunliche Sätze, welche die französische Futuristin hier den Frauen ihrer Generation entgegenschleudert und sie zum Handeln auffordert. An die Stelle weiblicher Zivilisiertheit und Sanftmut treten Wildheit und Grausamkeit, Attribute, die traditionell eher männlich besetzt waren. Und doch erscheint die Frau in ihrer Wollust entweder als Mutter oder als Geliebte, Rollen also, die sehr wohl traditionell den Frauen aus männlicher Perspektive auf den Leib geschrie-

5 Saint-Point, Valentine de: Manifest der futuristischen Frau, S. $22 \mathrm{f}$. 
ben wurden. Es ist eine Revolte, in der sich alles miteinander vermischt - genauso wie die Vorstellungen von Mannheit und Weibheit im Menschenbild von Valentine de Saint-Point.

Diese Aufforderung der Futuristin liegt seltsam quer zu dem doch bisweilen so einheitlichen Bild der Einforderung gleicher Rechte für die Frauen, einem Anliegen zeitgenössischer Feministinnen, gegen die sich Valentine de SaintPoint direkt und vehement richtet. Auch bei ihr ist der Diskurs auf eine Isotopie der Stärke, der Kraft und Energie, aber auch der Wildheit, der Grausamkeit und Brutalität gegründet. Dieser Diskurs unterscheidet sich freilich von dem Marinettis dadurch, dass er der Frau ebenfalls ihren Platz zuweist und ihre Wildheit eben nicht als zivilisatorische Bremserin des brutalen Mannes, sondern vielmehr als ,Anstachlerin‘ versteht, verbunden mit einer Betonung der Wollust, die sie in Freiheit ausleben kann. Jedenfalls dürften die Frauen die Männer nicht unter das Joch einer erbärmlichen Sentimentalität zwingen, so Valentine de Saint-Point am Ende ihres Manifests. Die Frauen sollten der Menschheit vielmehr Helden gebären: Helden, aus der Wollust geboren, für den kommenden Krieg gezeugt!

Man müsste in der Tat dem Denken und Schaffen von Valentine de Saint-Point näher nachgehen, ein Vorhaben, das ich im Rahmen dieser Vorlesung leider nicht bewerkstelligen kann. Gerade auch ihr antiimperialistischer Kampf gegen die europäischen Mächte ihrer Zeit weist sie als eine Denkerin und Intellektuelle aus, die ihre futuristische Perspektive später auf die außereuropäische Welt ausdehnte und der allgemeinen Begeisterung für eine Expansion Europas widerstand.

Ich möchte Ihnen gerne zumindest aus einem zweiten, auf den 11. Januar 1913 in Paris datierten Manifest von Valentine de Saint-Point eine Passage zitieren, welche wiederum in die Metaphorik von Stärke und Kraft eingebaut ist. Eine Passage, die alles nicht vor Gesundheit Strotzende gleichsam sozialdarwinistisch ausschaltet und den Leitgedanken der Wollust, also der sexuellen Dimension einer Revolution, einer Umwertung aller Werte, im nietzscheanischen Sinne vorführt, wie er später - vor allem dann bei den Surrealisten - von Gewicht sein sollte. Später wird uns Georges Bataille mit seiner Histoire de l'œil zu einem Statthalter derartiger Gedanken werden, nicht zuletzt auch in Hinblick auf das Frauenbild, das er vertreten wird. Aber wenden wir uns nun Valentine de Saint-Points Futuristischem Manifest der Wollust zu:

Die Wollust ist der Ausdruck eines Wesens, das über sich selbst hinaus geworfen wird; sie ist die leidvolle Lust der Vollendung des Fleisches, das freudige Leid eines Aufblühens; sie ist die fleischliche Vereinigung, gleich welche Geheimnisse die Wesen vereinen; sie ist die sensorische und sinnliche Synthese eines Wesens bei der größtmöglichen Befreiung seines Geistes; sie ist die Kommunion einer Parzelle der Menschheit mit dem gesamten Gefühlsempfinden der Erde; sie ist das panische Erschauern einer Parzelle der Erde. 
Die Wollust ist die fleischliche Suche des Unbekannten, so wie die Vergeistigung dessen spirituelle Suche bildet. Die Wollust ist die Geste des Schaffens, sie ist die Schöpfung. [...] Die Kunst und der Krieg sind die beiden großen Manifestationen der Sensualität; die Wollust ist ihre Blume. [...] Angesichts der Wollust gilt es, bewußt zu agieren. Man muß aus der Wollust das machen, was ein intelligentes und raffiniertes Wesen aus sich selbst und seinem Leben macht; man muß aus der Wollust ein Kunstwerk machen. ${ }^{6}$

Die Wollust wird in diesem Manifest als Dimension einer fundamentalen Befreiung und zugleich als Dimension einer Steigerung des Lebensgefühls gesehen, wobei sie - wie die Liebe ${ }^{7}$ - mit einem unstillbaren Erkenntnisdrang gekoppelt ist, der sich auf die gesamte Schöpfung richtet. Dabei erscheint die Wollust gerade nicht als die irrationale Gegenseite einer rational durchgearbeiteten Existenz, sondern wird ihrerseits zu einer raffinierten Erfahrung, einem lebendigen Erleben und schließlich zu einem Kunstwerk, in welchem der ganze Mensch und mehr noch die gesamte Schöpfung zum Ausdruck kommen. Vergessen wir hierbei aber nicht, dass in diesem Manifest einer Futuristin und Frau das Erleben der Wollust für die Frauen offen eingefordert und damit ein sexuelles Tabu jener Zeit gebrochen wird!

Die Sinne und die Sinnlichkeit überlagern alles - und warum nicht auch den Sinn? Kunst und Krieg als herausragende Manifestationen der Sinnlichkeit sind in dieser Sicht auf Körperlichkeit, die in der Tat vieles von Nietzsche einzuholen scheint, nun nicht im Ibsen'schen Sinne von Geschlechterkrieg geleitet, sondern vielmehr in einer wechselseitigen Anstachelung, einer immer größeren Freisetzung von Energie verankert. Potenziert katapultiert diese sich und die Körper (wie die Menschen) in eine neue Phase der Zukunft, eine offenere, freiere Zukunft. Die Wollust wird zu jener Kraft, der entscheidende Bedeutung zukommt; und sie ist keineswegs mehr nur das Privileg männlicher Erfahrung, sondern wird unverkennbar in einem weiblichen Erleben verankert. Lust und Wollust erscheinen nicht als Nebenprodukte eines zeitweisen Verlusts der Ratio, sondern bezeichnen einen kreativen, schöpferischen Mittelpunkt menschlichen Erlebens. Kunst und Literatur werden so zu fundamentalen Ausdrucksformen eines Lebenswissens und Erlebenswissens, die im Zusammenspiel von Kunst und Krieg zugleich zu einem Überlebenswissen werden. Wir sind hier weit entfernt von männlicher Vorherrschaft und Beherrschung weiblicher Lust und Wollust.

Nicht allein die Intensität der Erfahrung und die Wildheit allen Lebens sind gemeinsame Nenner mit Marinettis Futurismus, sondern auch - wie wir sahen -

6 Saint-Point, Valentine de: Futuristisches Manifest der Wollust. In: Asholt, Wolfgang / Fähnders, Walter (Hg.): Manifeste und Proklamationen der europäischen Avantgarde (1909-1938), S. 29.

7 Vgl. hierzu Ette, Ottmar: LiebeLesen. Potsdamer Vorlesungen über ein großes Gefühl und seine kreative Aneignung (2020). 
der Heroismus und nicht zuletzt der unbedingte Krieg. Kehren wir also an dieser Stelle wieder zum Gründungsmanifest des Futurismus zurück, einem Text, der in der Tat auch im weiteren Verlauf der Entwicklung des Futurismus einerseits und der historischen Avantgarden andererseits eine wichtige Rolle spielen sollte: ebenso mit Blick auf die Inhalte wie die künstlerisch-literarischen Formen! Natürlich waren auch andere Manifeste des Futurismus, insbesondere jene des italienischen Malers Boccioni, für dessen Entfaltung von großer Bedeutung. Doch Boccioni, der bei der Führung der Futuristen mit Marinetti zu rivalisieren versuchte, fiel im Krieg ohne Feindeinwirkung von seinem Pferd und fand damit einen Tod, den wir bereits in der postmodernen Spiegelung der historischen Avantgarden bei Enrique Vila-Matas liebevoll ausgemalt vorgefunden hatten. Auch für die Futuristen galt: Nicht immer ist der Tod im Krieg heroisch ...

Erinnern wir uns noch einmal an die Passagen aus dem Gründungsmanifest der Futuristen! Darin zieht die Erzählerfigur das Automobil und dessen Formgebung der als klassisch schön angesehenen Statue der Nike von Samothrake vor, jener Siegesgöttin also, deren Statue im Louvre steht und die Marinetti wohl in Paris gesehen haben dürfte. Eben hier aber setzt er sozusagen auf der obersten Ebene kanonisierter Schönheit sein künstlerisches Tun zugunsten einer Entfaltung und Durchsetzung einer neuen Schönheit ein, wobei nicht nur die Einführung des Neuen an sich, sondern die Zerstörung des Alten insgesamt als zwei Seiten ein und derselben Medaille des Bruchs mit dem Herkömmlichen, mit dem Traditionellen erscheinen. Weibliche Schönheit ist für Marinetti out, eine Tatsache, die auch bei ihm die Tradition der Misogynie auf den Spuren Nietzsches nahelegt. Nicht umsonst ist sein Schönheitsbegriff - wie übrigens auch der von Valentine de Saint-Point - an einer Körperlichkeit orientiert, die vor Kraft, Stärke und Energie nur so strotzt, die also an einer Gesundheit ausgerichtet ist, angesichts derer das Schwache, Kranke und auch Behinderte letztlich verschwinden müssen. Wiederum lassen sich leicht Parallelen zum nicht nur italienischen Faschismus aufzeigen.

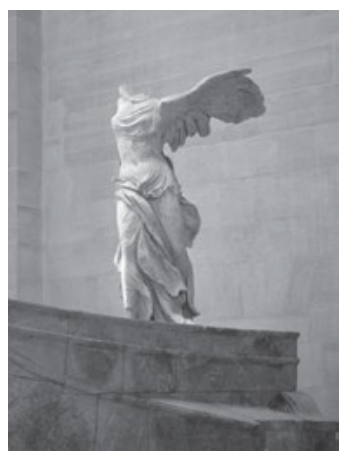

Abb. 22: Nike von Samothrake, um 220-185 v. Chr. 


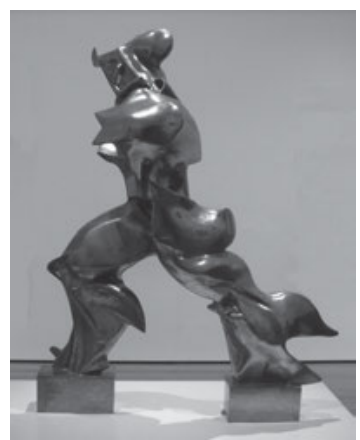

Abb. 23: Umberto Boccioni: Einzigartige Formen der Kontinuität im Raum, 1913.

Vor diesem Hintergrund wird auch deutlich, warum Marinetti nun in der folgenden These seines „Ersten Willens“ den Mann besingt, der das Steuer in der Hand hat, eine Art Übertragung des Bildes vom Steuermann aus dem marinen Bereich, wo es schon bei Gabriele d'Annunzio von größter Bedeutung war, auf den Bereich der Geschwindigkeit an Land. Dabei war es nur eine Frage der Zeit, bis ein solches Ideal auch in die Lüfte projiziert werden konnte, wo es in der Aviatik rasche Verbreitung fand - gepaart mit ungehemmter Heldenverehrung. Denn die sagenumwobenen Luftkämpfe der tollkühnen Piloten des Ersten Weltkriegs lagen nur noch wenige Jahre entfernt. Noch heute ist das Besucherrestaurant am Flughafen Tegel nach dem „Roten Baron“ benannt.

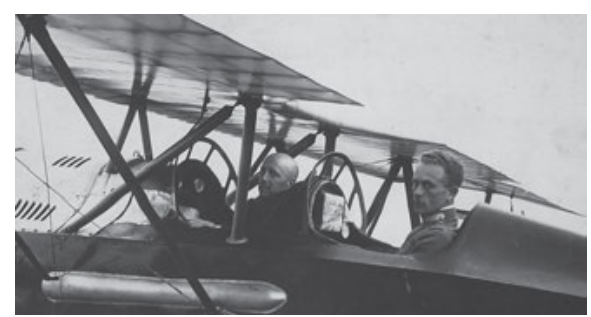

Abb. 24: Gabriele D’Annunzio (links) und Kapitän Natalio Palli während ihres Fluges über Wien, 1918.

Kommen wir zur neunten These, der uns ja bereits bekannten Verherrlichung des Krieges! Sie steht in Zusammenhang mit dem Lobpreis von Stärke und Gesundheit, womit sich auch die Bezeichnung des Krieges als einzige Hygiene der Welt erklärt, als „Guerra sola igiene del mondo“, wie es auch an anderer Stelle mehrfach in Marinettis Texten heißt. Von hier aus führt die Spur sicherlich direkt zur Rassengesetzgebung, wie wir sie später in den dreißiger Jahren im nationalsozialistischen Deutschland sehen werden, eine Problematik, die ich an dieser Stelle kaum zu erläutern brauche. Unsere offene Nachkriegsgesellschaft hat derartige Vorstellungen geächtet; und doch tauchen sie unvermittelt wieder in der neuen Rechten auf, so als hätte es keine Millionen von Ermordeten gegeben. 
An dieser Stelle möchte ich zumindest kurz auf einen der möglichen Bezugstexte und zugleich Vorläufer Marinettis hinweisen, auf Friedrich Nietzsche, der in seinen Überlegungen zur „gaya scienza“ ebenfalls auf diese Problematik zu sprechen kam. So heißt es in Die fröhliche Wissenschaft prophetisch:

\begin{abstract}
Unser Glaube an eine Vermännlichung Europas: Napoleon verdankt man's (und ganz und gar nicht der Französischen Revolution, welche auf „Brüderlichkeit“ von Volk zu Volk und allgemeinen blumichten Herzens-Austausch ausgewesen ist), dass sich jetzt ein paar kriegerische Jahrhunderte aufeinanderfolgen dürfen, die in der Geschichte nicht ihresgleichen haben, kurz, dass wir ins klassische Zeitalter des Kriegs getreten sind, des gelehrten und zugleich volkstümlichen Kriegs im größten Maßstabe (der Mittel, der Begabungen, der Disziplin), auf den alle kommenden Jahrtausende als auf ein Stück Vollkommenheit mit Neid und Ehrfurcht zurückblicken werden: - denn die nationale Bewegung, aus der diese Kriegsglorie herauswächst, ist nur der Gegenschock gegen Napoleon und wäre ohne Napoleon nicht vorhanden. Ihm also wird man einmal es zurechnen dürfen, dass der Mann in Europa wieder Herr über den Kaufmann und Philister geworden ist, vielleicht sogar über „das Weib“, das durch das Christentum und den schwärmerischen Geist des 18. Jahrhunderts, noch mehr durch die „modernen Ideen“ verhätschelt worden ist. ${ }^{8}$
\end{abstract}

In dieser eindrucksvollen Passage findet sich im Grunde schon ein gut Teil jenes Arsenals, das später dann von den Futuristen - und nicht nur von diesen - in Bezug auf eine Verherrlichung des Krieges und der Männlichkeit entfaltet werden sollte. Wir erleben eine ungeheure Zelebration des Krieges, für dessen Verbreitung am Ausgang des 19. Jahrhundert historisch nicht gänzlich unzutreffend Napoleon verantwortlich gemacht wird. Denn ohne die napoleonischen Expansionskriege wäre das „nationale Erwachen“ vieler Länder Europas sicherlich anders verlaufen - eine Tatsache, die freilich nichts am in Frankreich nach wie vor vorhandenen Napoleon-Kult geändert hat.

Mit der Lobpreisung des Krieges ist bei Nietzsche durchaus auch eine Kritik des Nationalismus und einer überzogenen Deutschtümelei verbunden, was man später geflissentlich übersehen oder überlesen hat. Doch ist in dieser wie auch in vielen anderen Passagen in der Tat ein Bild vom Mann, ein Männerbild und mehr noch ein Männlichkeitsbild entfaltet, von dem sich später die unterschiedlichsten Maskenbildner der Diktatoren Europas - und auch außerhalb Europas die entscheidenden Inspirationen besorgen konnten. Es ist ganz unzweifelhaft, dass in unserer Gesellschaft noch immer Elemente dieses Bildes fortexistieren und politisch wirksam sind. So wurde ein neues Menschenbild entwickelt, das im eigentlichen Sinne ein neues Männerbild war, welches freilich herkömmliche Züge des Patriarchalischen nur fortschrieb. Wir finden hierin keinen Bruch mit

8 Nietzsche, Friedrich: Die fröhliche Wissenschaft, S. 236. 
den, sondern bestenfalls ein Update der bisherigen historischen Ausprägungen vor.

Allein auf die Entwicklung und Weiterentwicklung dieses Männerbildes ließe sich ein ganzes Semester verwenden, worauf wir aber - wohl zu unser aller Entlastung - verzichten wollen! Der Krieg erweist sich in seiner gefeierten Herrlichkeit aber auch hier - in seiner internen Ankopplung an eine ganz bestimmte Körperlichkeit - als Dreh- und Angelpunkt der in die Zukunft projizierten Wünsche und Erwartungen, welche im 20. Jahrhundert blutig und zusammen mit millionenfachem Mord in Erfüllung gehen sollten. Für letzteren freilich den Philosophen verantwortlich zu erklären, schiene mir eine ahistorische Verkürzung. Friedrich Nietzsche gehörte jedoch zu den Entwicklern und Lieferanten jener Textbausteine, welche die Welt in die schlimmste Jahrhunderthälfte ihrer Geschichte stürzte.

Ein weiteres, im Futurismus immer wiederkehrendes Textelement ist die rücksichtslose Zerstörung der Museen und Bibliotheken wie auch - in der entsprechenden Erweiterung - aller Bildungsinstitutionen überhaupt. Alles, was an Bildungstraditionen anknüpft, besonders wenn diese akademischen Zuschnitts sind, wird einer vorsätzlichen, programmatischen Zerstörungswut preisgegeben. Buchstäblich auf der Abschussliste stehen für die Futuristen insbesondere auch die Professoren, die sozusagen als lebendige Museen und mehr noch Bibliotheken fungieren und die Hüter einer Tradition sind, die es ein für alle Mal zu vernichten gilt. Im Grunde alles, was die Vergangenheit bewahrt, was also ein wenig nur nach Tradition und Traditionssicherung riecht, wird unbarmherzig all jenen Dingen zugerechnet, die ausgerottet werden sollen. Und das Vernichten und Verbrennen wird zu einem Spektakel eigener Schönheit, eigener ästhetischer Faszination ...

Alles der Vergangenheit, dem „passato“ zugeordnete Traditionelle und Archivarische wird von den italienischen Futuristen der Kategorie „passatismo“ zugeordnet und für grundsätzlich unwürdig befunden, in die futuristische Zukunft miteinzugehen. Gerade die Museen als Produkte des 19. Jahrhunderts, die an der Jahrhundertwende eine erhebliche substanzielle Ausweitung erfahren hatten, werden von den Futuristen mit Verachtung gestraft und der Zerstörung überantwortet. Daneben aber sind es auch Moralismus und Feminismus, also auf bestimmte Zwecke gerichtete Bewegungen und Weltanschauungen, die eine klare Hierarchie und Wertewelt etabliert hatten. Sie sollen ebenso vernichtet werden wie der Utilitarismus, der mit seiner angelsächsisch geprägten buchhalterischen Zweckrationalität ja bereits auf der Negativliste des Fin de siècle gestanden hatte.

Es handelt sich bei alledem um gesellschaftliche Elemente und Bewegungen, die bereits für Friedrich Nietzsche einer überkommenen Zeitepoche anzugehören 
schienen. Ihre Zeit war nun für die Futuristen abgelaufen. Unter Feminismus verstehen sie ganz wie Marinetti keineswegs nur eine bestimmte gesellschaftliche Bewegung, die sich für die Rechte und die Gleichstellung der Frauen in den europäischen Gesellschaften einsetzt, sondern ebenso alle Überlegungen, die in irgendeiner Weise den Frauen zugutekommen. Misogynie ist an der Tagesordnung und wird gesellschaftsfähig: Frauenfeindlichkeit ist als zentrales Element in die Entwürfe futuristischen Lebens eingegangen. Dass es auch Gegenentwürfe gab, haben wir bei unserer Beschäftigung mit der futuristischen französischen Dichterin Valentine de Saint-Point gesehen.

Doch noch ein letztes Mal zurück zu Marinettis Gründungsmanifest! Der elfte und letzte Punkt des Manifests betrifft die großen Menschenmengen, ein Thema, das wir ja bereits beim Auftauchen der Kunstavantgarde am Horizont erscheinen sahen, war der Künstler doch eben jener Vermittler und Transmitter, dem es gelingen sollte, die gesellschaftlichen Massen auf seine Seite zu bringen und für eine weitere, futuristisch verstandene Gestaltung der künftigen Gesellschaft zu gewinnen. Schon für Gabriele d’Annunzio war die Problematik der Masse und deren Prägung und Leitung - unter Einschluss des Entwurfs von Führerfiguren eine ganz zentrale Thematik. Ihre politischen Konsequenzen lagen auf der Hand! Zugleich wird die urbane Dimension derartiger Aufrufe und Proklamationen deutlich, ist doch der Anspielungshorizont mit Blick auf die zu bewerkstelligende und ins Auge gefasste Revolution und den angezielten Adressatenkreis unmittelbar auf ein städtisches Publikum eingeengt. Hier gilt es also, von Beginn an den Futurismus als eine vorrangig urbane Bewegung zu begreifen.

Filippo Tommaso Marinetti ließ es nicht bei diesem ersten Manifest bewenden: Er legte sofort mehrere Texte nach, darunter insbesondere seinen Debütroman. Er erschien noch im selben Jahr 1909 in französischer Sprache unter dem Titel Mafarka le futuriste in Paris. Kurze Zeit später wurde er in italienischer Übersetzung von Marinettis Sekretär publiziert. Es handelte sich in der Tat um jenen ersten futuristischen Roman, den er - so Marinetti kommentierend - seinen futuristischen Brüdern versprochen hatte.

Es kann uns wahrlich nicht überraschen, dass die zentralen Figuren dieses Romans allesamt Männer sind. Wenig überrascht uns auch die Tatsache, dass es im Grunde vor allem um kriegerische Auseinandersetzungen und kriegerischkämpferische Entschlossenheit geht. In einer Ansprache des Romanhelden Mafarka dreht sich folglich alles auch um eben jene Dimensionen, welche wir bereits als Orientierung an der Maschine, an der körperlichen Kraft und männlichen Energie, aber auch als Ablehnung und Verachtung der Frau in Marinettis Manifest kennengelernt hatten. Es verwundert uns daher auch nicht, dass Mafarka ohne Zutun einer Frau gleichsam in einer Produktionsanstalt einen Sohn hervorbringt, ein wichtiger Gebärvorgang und Herstellungsprozess, sind doch 
auf diese Weise die Frauen gleichsam ihrer ,naturgegebenen' Mutterschaft und damit produktiven Funktion innerhalb der menschlichen Gemeinschaft verlustig gegangen.

Mafarkas Sohn ist konsequenterweise eine Art Kombination aus Mensch und Maschine: ein Flugzeug-Mensch, der von nun an die Perspektive aus der Luft in die Literatur einbringt. ${ }^{9}$ An dieser Stelle darauf verwiesen, dass Max Aub in seinem Roman über einen Avantgardisten namens Jusep Torres Campalans - flunkernd wie so oft - darauf aufmerksam machte, dass der Kubismus sich deswegen Kubismus nenne, weil auf Grund der Wahrnehmung aus der Luft die kleinen Häuschen am Boden, aus verschiedenen Perspektiven betrachtet, fast wie Würfelchen, eben „cubos“, aussahen. Dieses Element der Wahrnehmung aus der Luft ist also - soweit dürfen wir Max Aub sehr wohl folgen - ein überaus wichtiges und wahrnehmungsveränderndes Element der reichen Beziehung zwischen Literatur und Aviatik - mit Folgen weit über beide Gebiete hinaus.

Die Transposition von Mafarka le futuriste in eine Vorzeit und nach Nordafrika sollte uns an die Tatsache erinnern, dass Marinetti als Kriegsberichterstatter 1912 in Nordafrika, genauer in Libyen, tätig war. In seinem Erzähltext entfaltet er Phantasien einer ungeheuren kriegerischen Szenerie mit Massenmorden und brutalsten Vergeltungsmaßnahmen, welche in der Realität nur noch - wenn überhaupt - durch die folgenden beiden Weltkriege übertroffen werden sollten. Wir wohnen einem hemmungslosen Morden, einer durch nichts gebremsten Gewaltverherrlichung bei. Der entfesselten Soldateska werden im Übrigen in diesem Roman Dutzende, ja Hunderte von jungen Frauen zum Opfer gebracht; auch dies ein futuristischer Zug, der sich nicht nur in den Manifesten angekündigt, sondern in Marinettis späteren Texten künstlerisch beziehungsweise literarisch umgesetzt wurde.

Die Apotheose der Gewalt und deren ästhetischer Genuss mögen Ihnen zutiefst zuwider sein und ich gestehe gerne, dass diese Ästhetik der Zerfleischung mich zutiefst abstößt: Aber ferne ist sie uns nicht! Ich meine damit nicht die schauerliche Ästhetik und Bilderwelt unserer fernen und doch so nahen Drohnenkriege, sondern zum Beispiel die Reaktion von Karlheinz Stockhausen in einer Pressekonferenz auf die kurz zuvor erfolgten Angriffe auf das World Trade Center in New York. Dort gab der vielleicht berühmteste Komponist des 20. Jahrhunderts und avantgardistische Musiktheoretiker vor laufenden Aufnahmegeräten der Journalisten unter anderem zu Protokoll: „Also, was da geschehen ist, ist natürlich - und jetzt müssen Sie alle Ihr Gehirn umstellen - das größte Kunstwerk, was

9 Vgl. Ingold, Felix Philipp: Literatur und Aviatik. 
es je gegeben hat." ${ }^{10}$ Sie sehen: Die brutalen Terroranschläge von New York, die Tausenden von Menschen das Leben kosteten, können von einem Künstler und Theoretiker unserer Tage ,einfach so mal eben' zum größten Kunstwerk um-deklariert und damit ästhetisch zugänglich gemacht werden! Karlheinz Stockhausen stand darin - ob er sich dessen bewusst war oder nicht - ganz in der Tradition der europäischen Futuristen.

Der heroische Sohn von Marinettis Mafarka ist also eine Art Mischung aus einem Automaten und einem anthropomorphen Wesen, eine Art menschliche Flugmaschine, die konstruiert und zusammengesetzt wird wie andere Maschinen auch. Während ich dies schreibe, höre ich gerade im Rundfunk, dass es im Bereich der Sportmedizin längst zu einem Thema nicht zuletzt auch wissenschaftlicher Veröffentlichungen geworden ist, gentechnisch bereits die Koordinaten noch ungeborenen Lebens so zu verändern, dass sich hieraus geradezu notwendig Spitzensportler entwickeln müssen. Die futuristischen Ideen werden somit Stück für Stück Wirklichkeit, ganz gleich, wie wir derartige Phantasien und die futuristische Imagination auch immer ethisch und moralisch bewerten mögen.

Über diese Dimensionen hätte schon ein Friedrich Nietzsche nur gespottet; und ebenso erginge es uns auch beim Italiener Marinetti. Mafarka ist schon den berühmten Schritt weiter: Er hat die Moral - wie von Nietzsche gewünscht bereits hinter sich gelassen. Daher gibt Mafarka seinem Sohn eine Reihe von Orientierungen mit, hinter denen wir zum Teil simple Umkehrungen der christlichen Moral - etwa die Verkehrung der Nächstenliebe in die absolute Selbstliebe erkennen können. Die nietzscheanische „Umwertung aller Werte“ findet in den Programmen des Futurismus ihren ästhetischen Ausfluss.

Felix Philipp Ingold hat in seinem schönen Buch Literatur und Aviatik Marinettis Roman einige Seiten gewidmet und zurecht darauf hingewiesen, dass mit „diesem scheinbar trivialen Konglomerat aus lyrischen Versatzstücken und dramatisch verdichteten Traumbildern, aus Heldenepos und Abenteuerroman“ exemplarisch vorgeführt werden sollte, wie die literarische Umsetzung der Thesen seines ersten Manifests zu erfolgen hätte. ${ }^{11}$ Der propagandistische Unterton des Romans ist nicht zu überhören, mehr noch: Marinettis Text setzt Programmatik in Propaganda um! Politik und Kunst stehen Seite an Seite. Gewiss können wir in Mafarka und seinem Sohn eine wichtige Traditionslinie des Übermenschen erkennen, die sich rückwärts zweifellos hin zu Nietzsches „Übermensch“ und nicht weniger zu Alfred Jarrys „Supermâle“ erstreckt - einen Roman, den wir in

10 Vgl. den Mitschnitt in BR Klassik (16.9.2001).

11 Ingold, Felix Philipp: Literatur und Aviatik, S. 75. 
unserer Vorlesung nicht besprechen können, dem aber eine große Bedeutung für Marinettis Entwürfe zukommt. Doch dies ist längst nicht alles!

Denn andererseits besteht bis heute eine Nachfrage nach, aber auch Nachfolge von Mafarka, die sich bis zu den Filmen der Monsterklasse, den Comics und BDs fortschreiben lässt. Auch ein Tarzan und weit mehr noch Batman oder Superman gehören in die Genealogie futuristischer Phantasien. Das Erbe des Futurismus ist beeindruckend, auch wenn sich die genetischen und genealogischen Linien nicht immer direkt rekonstruieren lassen. Doch Omnipräsenz und Fortleben futuristischen Gedankenguts - wenn auch in veränderten Konstellationen und anderen soziokulturellen Kontexten - sind nicht zu übersehen!

Vor diesem Hintergrund konnte es Marinetti nur gefallen, dass die italienische Justiz ihn und seinen Roman anklagte wegen Verletzung der Schicklichkeit, letztlich aber freisprechen musste, was dem Roman, von Marinetti kräftig unterstützt, eine ungeheure Publicity verschaffte. Schon die Immoralismus-Prozesse gegen französische Literaten des 19. Jahrhunderts hatten vor allem gezeigt, dass sie die Verkaufserfolge von Texten im Allgemeinen sicherstellten. ${ }^{12}$ Zweifellos dürfen wir in Mafarka le futuriste zugleich die Konzipierung einer faschistischen Literatur erkennen: eine Verbindung, die übrigens Marinetti während der Mussolini-Zeit mehrfach selbst betont hatte.

Ich möchte mich diesem Roman, der an Szenen der Grausamkeiten und Zerstörungswut unglaublich dicht ist und dies mit einer an Klischees überreichen Sprache vorführt, nicht ausführlich widmen. Jedoch will ich beispielhaft eine Passage herausgreifen, die wiederum mit der Wichtigkeit von Wahrnehmung aus der Luft und Aviatik insgesamt zu tun hat und sich auf den Flug bezieht, mit dem der Sohn Mafarkas, Gazourmah, den Planeten Erde verlässt und sich dem Mars zuwendet. Es handelt sich dabei um einen Raum-Flug, der zugleich mit der galaktischen Sphärenmusik in Verbindung gebracht wird und somit in gewisser Weise dem irdischen Chaos eine kosmische Ordnung, einen Kosmos jenseits des Planeten Erde entgegenstellt. Sie bemerken, dass dies Handlungs- und Kontextelemente sind, welche Ihnen aus Science-Fiction-Romanen wohlvertraut sind - und dass ich Ihnen die Grausamkeiten dieses Romans wirklich nicht zumuten will:

Plötzlich, als sich seine Flugweise änderte, bezauberte eine sanfte und seltsame Melodie seine Ohren. Er begriff sogleich, dass sie aus seinen Flügeln kam, die lebendiger und klangvoller waren als zwei Harfen, und er vergnügte sich, trunken vor Begeisterung, damit, diese

12 Vgl. Heitmann, Klaus: Der Immoralismus-Prozeß gegen die französische Literatur im 19. Jahrhundert. Bad Homburg - Berlin - Zürich: Verlag Gehlen 1970. 
harmonischen Kadenzen zu modulieren, indem er die Schwingungen Mal für Mal sehnsüchtig in die Länge zog und ihre exaltierte Wiederkehr immer höher schraubte.

Dergestalt verwirklichte sich in Gazourmahs Flug endlich die große Hoffnung der Welt, der große Traum einer totalen Musik ... Der Aufschwung aller Gesänge der Erde vollendete sich in seinen großen inspirierten Flügelschlägen! ... Hehre Hoffnung der Poesie! Wunsch nach Verflüchtigung! Edle Ratschläge des Qualms und der Flammen! $!^{13}$

Es geht hier um die Vision einer absoluten Welt, erfüllt von einer absoluten Musik, in welcher der totale Künstler eine totale Kunst hervorbringt, die das gesamte Universum erfasst: Es sind immer wieder diese Träume, welche all jene Futuristen begeistern, die sich um Marinetti scharen. Wir wohnen der künstlerischen Entstehung einer Welt bei, in welcher Leben und Kunst, Mensch und Maschine, Natur und Kultur miteinander eng verwoben sind und Harmonien entstehen lassen, wie sie bereits in der Antike erträumt wurden. Die Harfen mögen uns daran erinnern, dass wir es hier sehr wohl mit langanhaltenden Traditionen in der Kunst zu tun haben, auf die Marinetti durchaus zurückgriff, was ihn aber nicht daran hinderte, verbal mit aller vorhandenen Kunst zu brechen.

Lassen Sie uns aber jetzt diesem futuristischen und vom Faschismus gar nicht weit entfernten Roman schnell wieder Adieu sagen, dem Barbara Vinken vor einiger Zeit einen Aufsatz im Hinblick auf dessen Pulp-Ästhetik gewidmet hat, womit eine Art Ästhetik der ,Zermantschung', der Zerstörung, des Ausquetschens gemeint ist, in welcher die Arbeit auch schwelgt! ${ }^{14}$ Diese Zerstörung und ,Zermantschung 'ist übrigens eine Dimension, die wir bereits bei Alfred Jarry, etwa in seinem Ubu Roi und seiner „Chanson du décervelage“, später auch noch bei Boris Vian ausfindig machen können.

Widmen wir uns nun aber jener Dimension der Glorifizierung, die Sie auch am Ende dieses etwas hohl klingenden Auszugs aus Mafarka le futuriste zweifellos wahrnehmen konnten, und versuchen wir, die Marinetti'sche Schreibweise nun im Bereich der Lyrik etwas genauer unter die Lupe zu nehmen! Als Beispiel für die Dichtkunst Marinettis soll uns nun ein Text dienen, der sich irgendwo auf der Grenze zwischen Lyrik und Prosa bewegt und eben jene Thematik des Krieges, die wir nun sattsam kennen, mit einer neuen, zukunftsweisenden ästhetischen Dimension in Verbindung bringt - der Dimension der Simultaneität:

13 Marinetti, Filippo Tommaso: Mafarka le fututriste. Roman africain. Paris: E. Sansot 1909, S. $305 \mathrm{f}$.

14 Vgl. Vinken, Barbara: MAKE WAR NOT LOVE: Pulp Fiction oder Marinettis Mafarka. In: Asholt, Wolfgang / Fähnders, Walter (Hg.): Der Blick vom Wolkenkratzer: Avantgarde, Avantgardekritik, Avantgardeforschung. Amsterdam - Atlanta: Rodopi 2000, S. 183-206. 


\begin{abstract}
Ruhm der Poesie neuer Kriegs-Technizismen
Obgleich Experte für echte oder gefälschte Schlachten, genoss und genieße ich noch zahlreiche Momente staunender Freude am Tag des Feuers, den der Duce in Furbara und Santa Marinella dem Hitler auf elegante Weise darbot

Vom Morgengrauen an alles und jeder unter dem Kommando des Großen Neu-Italien, das auch technisch den imperialen Blitzkrieg gewann und nun als beharrliche Alchimistin der Zukunft günstige Verhältnisse vorbereitet

Wir befinden uns in einem riesigen chemischen Labor hochfliegender Gleichungen auf einem blau-flugzeuglichen Sonnen-Fresko [...]

Inzwischen erwachen die Bomber-Trimotoren mit wilder Freude und graben und wühlen im weiten dröhnenden Busen der Erde, wutentbrannt über so viele explodierende Tonnen - so viele $[. .$.

Ruhm jenen gewitzten Fläschchen voll explosiver italienischer Ideale ... ${ }^{15}$
\end{abstract}

Dieses Prosagedicht aus den Zeiten der Achse zwischen Rom und Berlin sowie der unverbrüchlichen Freundschaft zwischen Hitler und Mussolini, vor der ein Gabriele d'Annunzio den Duce durchaus gewarnt hatte, zeigt, dass auch nach der Erfahrung des Ersten Weltkriegs die Kriegstrunkenheit Marinettis nicht nachgelassen hatte. Die Simultaneität der Einschläge, der Bomberstaffeln, der Granaten usw. - und ich habe zu unser aller Freude vieles davon weggelassen! - zeigt, dass der Krieg für den italienischen Futuristen Marinetti - und er hatte unermüdlich für den Kriegseintritt Italiens geworben und Propaganda gemacht - für ihn noch immer das große ästhetische Spektakel war, das er sich zur radikalen Transformation der gesamten Welt ersehnte.

Marinetti „le futuriste“ erging sich in Lobpreisungen aller Art für dieses technisch-maschinenhafte Spektakel, da es eine große Simultaneität mit immer neuem Kriegsspielzeug herzustellen in der Lage war. Dichtkunst und die Literatur insgesamt stehen hier im Dienste einer politischen Propaganda, zugleich aber auch einer lebenspraktischen Umsetzung, die - wie wir sahen - für Peter Bürger oberstes Kriterium für die Avantgarde ist. Es geht um die Vorstellung einer Verschmelzung von Kunst und Lebenspraxis, um die Aufhebung der Grenze zwischen Leben und Kunst, ganz so, wie auch im auf den ersten Blick vom Krieg so verschiedenen Bereich der Wollust, der „volupté“, von Valentine de Saint-Point die Umsetzung des Körperlichen und der Erotik in Kunst eine Aufhebung dieser Grenzziehungen beabsichtigte. Die futuristische Kunst will gelebt, will ausgelebt werden!

Die großen und starken Verbindungen zwischen Futurismus und Faschismus sind keineswegs die einzigen politischen Optionen, wenn wir den Futurismus in seiner gesamten europäischen Spannbreite analysieren. Es wäre auch möglich

15 Marinetti, Filippo Tommaso: Poesia simultanea di una finta battaglia. In Ders.: Il poema non umano dei tecnicismi. Mailand: Mondadori 1940, S. 117 f. [Übers. Markus A. Lenz] 
gewesen, ein Bündnis am anderen Ende der politischen Skala zu nennen, wenn dieses auch weit weniger dauerhaft war. So könnten wir durchaus die Entwicklung des russischen Futurismus untersuchen, insofern sich diese Variante zeitweilig an der Oktoberrevolution und den verschiedenen Programmen der künstlerischen revolutionären Bewegungen im zusammengebrochenen Zarenreich orientierte. Denn auch dort lässt sich der Drang einer autonom gewordenen Kunst nach dem Leben absehen: mit dem Versuch dieser Seitenlinie des Futurismus, auf die Gesellschaft und die Lebenspraxis in Russland in direkter Weise einzuwirken und dabei auch eine führende, wegweisende, eben avantgardistische Stellung einzunehmen.

Zum Zeitpunkt des zuletzt analysierten Gedichts freilich hatten die politischen Akteure in den unterschiedlichen Ländern längst die Dinge so sehr in den Griff bekommen, dass es hier um einen wie auch immer geäußerten gesellschaftlichen Führungsanspruch futuristischer Künstler nicht mehr gehen konnte. Die futuristische Kunst orientierte sich vielmehr zunehmend an einer bereits veränderten gesellschaftlichen Lebenspraxis, zu deren Gehilfin sie wird. Gleichwohl - und auch dies sollten wir nicht vergessen - hat der Faschismus in seinen unterschiedlichen Ausprägungen eine Vielzahl futuristischer Ideen in die Tat umgesetzt, so dass die erste historische Avantgardebewegung in der Tat eine Sprengkraft entwickelte, die nicht nur die eigene Gesellschaft, sondern die gesamte Welt in Brand setzte.

Wir wollen an dieser Stelle zu einem weiteren, für die Entwicklung des Futurismus wie der historischen Avantgarden grundlegenden Manifest Marinettis kommen! Manifeste waren seine eigentliche Spezialität, sieht man einmal davon ab, dass er eben vor allem auch der große Macher, der große Propagator, der große Organisator war, der es verstand, werbetechnisch geschickt die Aufmerksamkeit auf eine anfangs sehr minoritäre Gruppe zu lenken und ihre künstlerischen Bemühungen gebührend ins Rampenlicht zu rücken. Die Auswahl zwischen den zahlreichen Manifesten Marinettis fällt uns nicht leicht!

Es wäre durchaus möglich, uns dem nach seinem Gründungsmanifest wohl bekanntesten Dokument des italienischen Futuristen zuzuwenden, dessen Titel bereits wieder auf Mord und Totschlag verweist: Uccidiamo il Chiaro di Luna (datiert auf April 1909) oder Tod dem Mondschein, wie der deutsche Titel lautet. Darin geht es in der Tat ständig um Morde, ja Massenmorde, die nunmehr aus der Perspektive der Luft ausgeführt werden, ist doch die futuristische Kampftruppe mit Aeroplanen bewaffnet, die Bomben abwerfen und aus kleinen Maschinengewehren auf die Menschen feuern. Diese können sie ja nicht mehr unterscheiden, sondern nur mehr noch als undifferenzierte Gruppen und vor allem als kollektive feindliche Horden wahrnehmen. Ihnen fallen dazu nur jene Bilder ein, die dank Julian Assange und WikiLeaks an die Öffentlichkeit kamen und diese völlig asymmetrische, mörderi- 
sche Kriegsführung zeigen? Dann liegen Sie nicht falsch, denn genau dies ist es: Massenmord! Ausgeführt freilich nicht von italienischen Futuristen, sondern der Führungsmacht der westlichen Wertegemeinschaft. Willkürliche Hinrichtungen verübt nicht mit Hilfe von Mitrailleusen aus tollkühnen Doppeldeckern, sondern von US-Kampftruppen, die aus Hubschraubern operierten und sich laut Übertragung tierisch über ihr gutes Zielwasser freuten.

Sehen Sie es mir bitte nach, dass ich noch einen kurzen Augenblick lang bei diesem futuristischen Text verweile, der auf unsere Zukunft ein so unbarmherziges Licht wirft! Die Befehle, auf diese Horden zu feuern, strukturieren den letzten Teil dieses Manifests, das wiederum eine Reihe narrativer Grundstrukturen enthält, so dass es eine Geschichte erzählt, die freilich in mehr als einem Sinne programmatisch ist. Wenn ich Ihnen das berühmte Video der US-Kampftruppen, das von WikiLeaks zugänglich gemacht wurde, einspielen würde, wären Sie Zuschauer eines von den Futuristen vorgedachten, imaginierten und von anderen in die Tat umgesetzten Happenings, für das die Worte ,unmenschlich` oder ,menschenverachtend' harmlose Euphemismen wären. Und doch: Die USA stürzen sich nicht auf jene, die in ihrem Namen diese unsäglichen Verbrechen begingen, sondern auf denjenigen, der die Bilder allgemein zugänglich machte.

Ich möchte auf dieses Manifest aus Zeitgründen aber nicht näher eingehen, sondern Ihnen gleichsam parallel hierzu etwas anderes vorführen, nämlich die veränderte Wahrnehmung aus der Luft, die sich in eben jener Zeit in Kunst wie Photographie reflektiert und analysiert sieht. Dazu möchte ich Ihnen zum einen die Originalphotographie vorlegen, die den Überflug von Wien durch die von Gabriele d'Annunzio geleitete Flugzeugstaffel am 9. August 1918 zeigt, und auf der Sie Abertausende von Flugblättern erkennen können, welche die italienischen Männer über der österreichischen Hauptstadt niederrieseln ließen. Die angegebene Flughöhe der Flugzeugstaffel Serenissima und damit auch die Höhe, aus der dieses Foto geschossen wurde, betrug wohl etwa 700 Meter. ${ }^{16}$

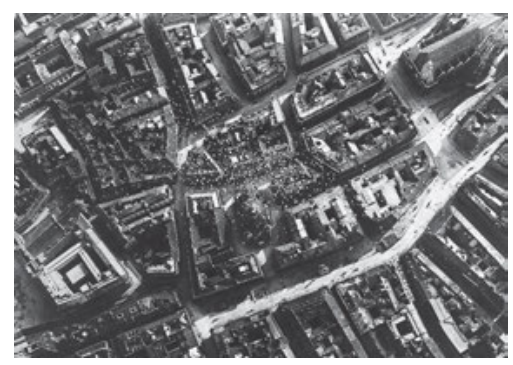

Abb. 25: Gabriele D’Annunzio: Flug über Wien und Abwurf tausender Flugblätter, 1918.

16 Vgl. Ingold, Felix Philipp: Literatur und Aviatik, S. 437. 
Ein zweites Bildelement ${ }^{17}$ verweist auf die Tatsache, dass durch den Blick auf die Welt aus der Vogelperspektive - die in der Literatur keineswegs neu war, wie etwa ein Blättern in Victor Hugos Notre-Dame de Paris und das Eröffnungskapitel „Paris à voile d'oiseau“ zeigt - eine Art Geometrisierung und Dynamisierung der Wahrnehmung und der Wahrnehmungsobjekte einsetzt, die sich in vielfältiger Weise auch künstlerisch bricht. Das Flugzeug wird zum zentralen Erfahrungsmittel, wobei das Element des Fliegens auch eine erotische Komponente besitzt. Dies erbrachten die psychoanalytischen Untersuchungen eines Sigmund Freud; aber schon zeitgenössische Plakatentwürfe zeigen uns dies in aller wünschenswerten Deutlichkeit. ${ }^{18}$ Dort sehen Sie den nach oben gereckten Frauenkörper einer in den Himmel zu den Flugmaschinen hinaufweisenden, ekstatisch gekrümmten jungen Frau; und auf einem zweiten Plakat die unserer heutigen Autowerbung nicht sehr fremde Drapierung einer akzentuierten Frau auf dem Flügel eines von einem Mann gesteuerten Aeroplans. Die Untersuchung der geschlechterspezifischen Rollenverteilung überlasse ich ebenso Ihrer Analyse wie die Parallelen zur heutigen Werbung!

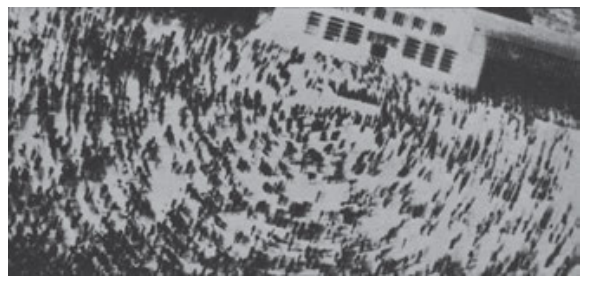

Abb. 26: Aviatorische Weltschau: Geometrisierung und Dynamisierung der Optik.

Ich möchte Ihnen gerne mit Hilfe dieser Photographien und Bilder aufzeigen, welche Bedeutung das Auftauchen des Flugzeugs am Himmel auch für die Alltagsund Kunst-Imagination der Zeitgenossen besaß: Der Mensch konnte nun fliegen, war bald schon Herr der Lüfte, machte sich auch dieses Element unseres Planeten untertan! Aus all diesen Aspekten erklärt sich einerseits die Besessenheit der Futuristen gerade auch vom Bewegungsmittel Flugzeug und andererseits die Tatsache, dass sich hieraus in der Tat eine andere Wahrnehmung von Landschaft und Stadt ergaben, in welcher der einzelne Mensch nicht mehr in Erscheinung tritt. Die Verbindung zum Krieg weist uns erneut auf unsere eigene Gegenwart, wo die aktuellen Flugzeugkanzeln vielleicht noch weniger - da über Bordgeräte gesteuert und mediatisiert - die Wahrnehmung des computergelenkt anzugrei-

17 Ebda., S. 476.

18 Ebda., S. 417. 

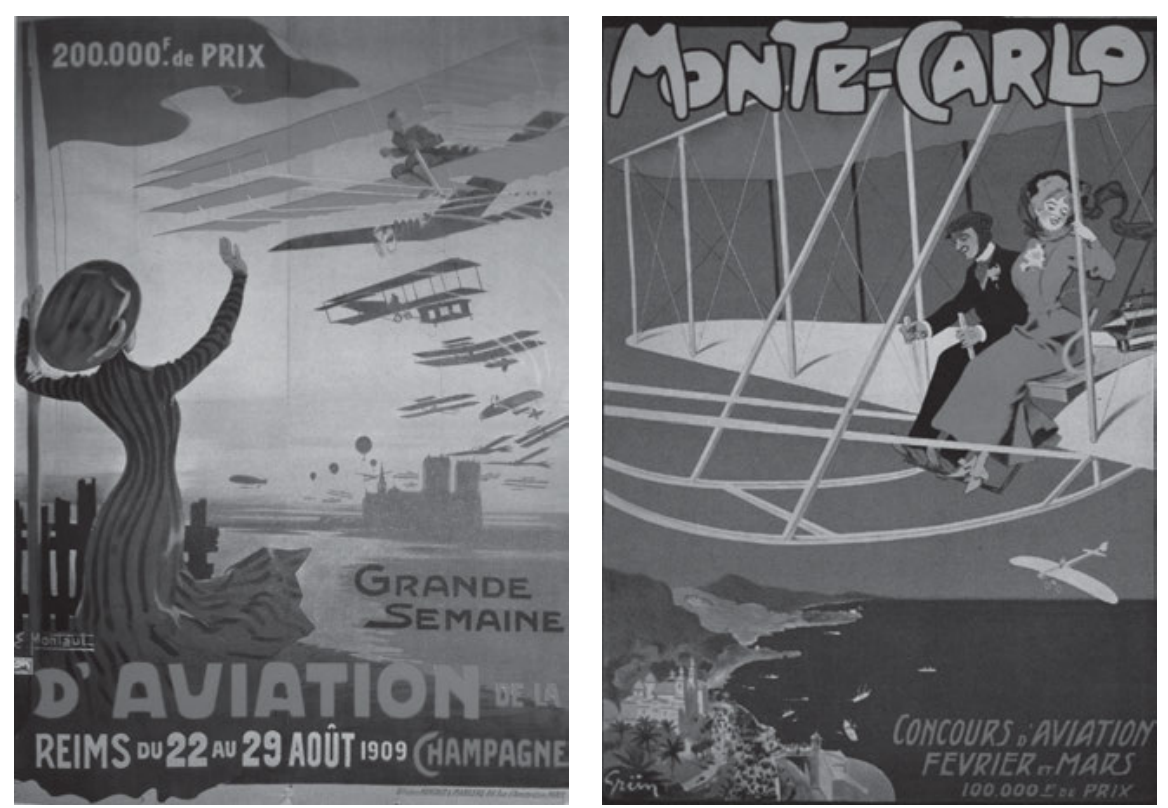

Abb. 27a und b: Zwei Flugplakate, 1909-1912.

fenden Individuums ermöglicht und zugleich wiederum verhindert. Ermöglicht, um möglichst zielgenau treffen zu können, verhindert aber, weil es sich nie um einen eigentlichen Menschen handelt, sondern bestenfalls um dessen Silhouette, um ein distantes Bild auf dem Bildschirm.

Eine Individualisierung erfolgte allerhöchstens in Form der berühmten tollkühnen Männer in ihren fliegenden Kisten und den vielen Legenden, die sich um die großen Kriegsflieger wie etwa den „Roten Baron“ von Richthofen gebildet haben. Ich hoffe, Ihnen vor diesem Hintergrund deutlicher vor Augen geführt zu haben, dass sich die Futuristen nur an die programmatische Spitze einer Bewegung setzten, die ausgelöst durch den technischen Entwicklungsschub die ganze Gesellschaft erfasste und die gesamte Wahrnehmungsstruktur menschlicher Sinne grundlegend veränderte.

Wir verfügen nun über die Voraussetzungen, die Problematik der AeroplanMetaphorik insgesamt zu erfassen und deren Umsetzung im künstlerischen und literarischen Bereich adäquat zu verstehen. Die enormen revolutionären und ästhetischen Veränderungen, welche von den Futuristen ausgehen, erfassen die gesamten Avantgarden wie auch weit darüber hinaus die Künste und Literaturen der ersten Jahrhunderthälfte. Sie sind von einer solch grundlegenden Veränderung gekennzeichnet, dass es nicht statthaft wäre, diese nur aus rein inner- 
literarischen oder rein politischen Gründen und Aspekten abzuleiten, ohne die technischen Transformationen und den dadurch ausgelösten Wandel in der Perzeption und Imagination miteinzubeziehen. Ganz so, wie die Futuristen Kunst und Leben nicht länger voneinander trennen wollten, so gilt es auch, die futuristische Kunst nicht von ihren sozioökonomischen, technologischen und politischen Kontexten abzulösen: Wir müssen alles als eine komplexe Einheit behandeln! 